\title{
BMJ Open Occupational exposure and risk of colon cancer: a nationwide registry study with emphasis on occupational exposure to zoonotic gastrointestinal pathogens
}

\author{
Janneke Duijster (D) , ${ }^{1,2}$ Lapo Mughini-Gras, ${ }^{1,3}$ Jacques Neefjes, ${ }^{2}$ Eelco Franz ${ }^{1}$
}

To cite: Duijster J, MughiniGras L, Neefjes J, et al. Occupational exposure and risk of colon cancer: a nationwide registry study with emphasis on occupational exposure to zoonotic gastrointestinal pathogens. BMJ Open 2021;11:e050611. doi:10.1136/ bmjopen-2021-050611

- Prepublication history and additional supplemental material for this paper are available online. To view these files, please visit the journal online. (http://dx.doi.org/10.1136/ bmjopen-2021-050611)

Received 02 March 2021 Accepted 27 July 2021

Check for updates

(c) Author(s) (or their employer(s)) 2021. Re-use permitted under CC BY-NC. No commercial re-use. See rights and permissions. Published by BMJ.

${ }^{1}$ Centre for Infectious Disease Control, National Institute for Public Health and the Environment, Bilthoven, The Netherlands

${ }^{2}$ Department of Cell and Chemical Biology, Oncode Institute, Leiden Universitair Medisch Centrum, Leiden, The Netherlands

${ }^{3}$ Institute for Risk Assessment Sciences, Utrecht University Faculty of Veterinary Medicine, Utrecht, The Netherlands

Correspondence to

Janneke Duijster;

janneke.duijster@rivm.nl

\section{ABSTRACT}

Objectives While colon cancer (CC) risk is associated with several lifestyle-related factors, including physical inactivity, smoking and diet, the contribution of occupation to CC morbidity remains largely unclear. Growing evidence indicates that gastrointestinal infections like salmonellosis could contribute to CC development. We performed a nationwide registry study to assess potential associations between occupation (history) and CC, including also those occupations with known increased exposure to gastrointestinal pathogens like Salmonella.

Methods Person-level occupational data for all residents in The Netherlands were linked to CC diagnosis data. Differences in the incidence of (overall, proximal and distal) CC among occupational sectors and risk groups were tested for significance by calculating standardised incidence ratios (SIRs) with 95\% Cls using the general population as reference group. Effects of gender, age, exposure duration and latency were also assessed.

Results Significant differences in CC incidence were observed only for a few occupational sectors, including the manufacturing of rubber and plastics, machinery and leather, the printing sector and the information service sector (SIRs 1.06-1.88). No elevated risk of CC was observed among people with increased salmonellosis risk through occupational exposure to live animals, manure or among those working in the sale of animal-derived food products (SIRs 0.93-0.95, 0.81-0.95 and 0.93-1.09 for overall, proximal and distal CC, respectively).

Conclusions The results of this study suggest that occupation in itself provides a relatively small contribution to CC incidence. This is consistent with previous studies where a similar degree of variation in risk estimates was observed. The lack of an association with the high-risk occupations for salmonellosis might be due to higher levels of physical activity, a known protective factor for CC and other diseases, of people working in the agricultural sector, which might outweigh the potential Salmonellaassociated risk of CC.

\section{BACKGROUND}

With over a million new diagnoses, colon cancer (CC) was the third most frequent malignancy worldwide in 2018. ${ }^{1}$ In The Netherlands ( $\sim 17$ million population), the agestandardised incidence rate of CC is 1.83 per
Strengths and limitations of this study

- This is the first study addressing the potential as sociation between gastrointestinal bacterial infections (in particular non-typhoidal Salmonella) and the development of colon cancer (CC) in relation to occupation.

- The association between a broad range of occupations and CC incidence was assessed in a nationwide cohort in a high-income country.

- Given the observed global increase in CC incidence among young adults ( $<50$ years), separate risk estimates were provided for overall CC in individuals aged $<50$ and $\geq 50$ years in relation to occupation.

- We could not control for confounding factors (eg, smoking and physical activity), which might affect the observed risk estimates.

10000 inhabitants. ${ }^{1}$ While the survival rates of patients with CC continue to improve as a result of screening programmes and targeted treatments, ${ }^{2}$ the past three decades have been characterised by an increase in the incidence of colorectal cancer among people aged $<50$ years in several high-income countries. ${ }^{3}$ In The Netherlands, the annual percent change of colorectal cancer between 2001 and 2016 was 2.1 for people aged 20-39 years and 2.3 for people aged 40-49 years. ${ }^{4}$ The reason for this increase remains largely unknown.

Apart from genetic background (ie, inheritable CC, such as hereditary nonpolyposis colorectal cancer and familial adenomatous polyposis), the main risk factors for CC comprise dietary and lifestyle factors, including the consumption of red and processed meat, smoking, alcohol consumption, obesity and limited physical activity. ${ }^{56}$ The latter factor in particular has been addressed in several studies showing that people with sedentary jobs (eg, white-collar workers) are at increased risk of colorectal and CCs. ${ }^{7}$ Occupational exposure to chemical 
compounds used in several industrial productions, such as leather, metals, plastic and rubber, as well as asbestos, has also been reported to increase the risk of CC. ${ }^{8-10}$ Moreover, in the past decade, the role of bacterial infections in cancer development has gained momentum. ${ }^{11}$ For the gastrointestinal system, these infections concern mainly Helicobacter pylori and Salmonella Typhi as causative agents of gastric cancer and gallbladder carcinoma, respectively, ${ }^{12} 13$ as well as (severe) non-typhoidal Salmonella infection for $\mathrm{CC}^{14-17}$ and colibactin secreting Escherichia coli strains for colorectal cancer. ${ }^{18}{ }^{19}$ Whether repeated, low-dose exposure to Salmonella leading to asymptomatic or paucisymptomatic infection, for instance in occupational settings, is also a risk factor for CC, remains unclear and has not yet been investigated.

While occupational exposure to carcinogens for among others lung and skin cancers, have been extensively documented, the role of occupation in CC epidemiology is complex and ambiguous. ${ }^{2021}$ Moreover, apart from a large study in five northern European countries making use of multiple-year census data, ${ }^{22}$ most studies have addressed only specific occupational groups (eg, nurses, farmers, asbestos plant workers), rather than the total employed population, and these studies did not consider the occupational risk cumulatively based on exposure history, but rather the effect of occupation at a given moment in time. ${ }^{23-25}$ The primary aim of this nationwide registrybased cohort study was to assess the potential association between occupations with known increased exposure to zoonotic pathogens like Salmonella and CC incidence. We also extended the analyses to the whole spectrum of occupational exposures in The Netherlands between 1999 and 2016. Rectal cancers were not included in the analysis, as in a previous Dutch cohort study, a significant association between non-typhoidal Salmonella and CC was only found for the proximal part of the colon. ${ }^{14}$ Moreover, colon and rectal cancers differ from each other with respect to molecular carcinogenesis, clinical symptoms and risk factors, with for instance high levels of physical activity being a protective factor for colon but not rectal cancer. ${ }^{26}$

\section{METHODS}

\section{Data registries and linkage}

We assessed the association between occupation and CC risk by linking two national registries in The Netherlands. Statistics Netherlands (CBS) provided person-level, de-identified occupational history data for all Dutch residents at any moment in time, including changes in occupational group, specific functions therein, and employer, between January 1999 and December 2016. The occupational groups were coded according to the European Nomenclature of Economic Activities (NACE) based on the economic activity of a registered company providing employment. ${ }^{27}$ The NACE data are structured in four hierarchical levels (sections, divisions, groups and classes) by a five-digit code, allowing for analyses at different levels, as described in more detail elsewhere. ${ }^{28}$ The second data set was retrieved from The Netherlands Cancer Registry and contained 135909 CC diagnoses between January 2000 and December 2016, of which 74254 pertained to the proximal colon (International Classification of Diseases, 10th Revision (ICD-10) codes C180-C185) and 61655 to the distal colon (ICD-10 codes C186, C187).

\section{Sectors and risk groups}

First, we assessed the risk of CC at the NACE-level of division where all occupations are mutually classified into 86 different divisions (hereafter referred to as 'sectors'). ${ }^{25}$ We then defined three risk groups (based on the most detailed NACE-codes of the occupations), including occupations with contact with live animals or animal manure (eg, farmers, veterinarians), occupations involved in the production and handling of animal-derived food products (eg, cooks, bakers) and occupations involved in the sale of animal-derived foods (eg, butchers). This risk group classification was in accordance with the risk groups used in a previous study assessing the occupational risk of Salmonella infection. ${ }^{27}$

\section{Statistical analysis}

For the data analysis, individuals entered the at-risk period after 1 year of registered employment in a given occupational group of interest (ie, a sector or a risk group) or when reaching the age of 20 years, whichever came last. Hence, the earliest date of onset of follow-up was 1 January 2000. CC diagnosis under the age of 20 years is rare (ie, there were only 14 CC diagnoses in people aged 10-19 years during the total study period) and this is mostly the result of inheritable factors. ${ }^{29}$ The follow-up period ended at the date of CC diagnosis (ie, the event of interest), date of death or the end of the study period (31 December 2016), whichever came first. No censoring on emigration was applied. Individuals were allowed to be included in multiple sectors or risk groups simultaneously. We excluded people from the analysis who were diagnosed with CC before onset of employment in a sector or risk group or were diagnosed after less than 1 year of exposure. First, we calculated the incidence rates (IRs) of CC (overall and per subsite) per 10000 personyears at risk in the total employed population, by gender, age group ( $<50$ and $\geq 50$ years), duration of exposure (ie, the number of years employed $(<2 ; 2-4 ; 5-9 ; \geq 10$ years $)$ ) and latency (ie, the number of years since the onset of exposure $(1-4 ; 5-9 ; \geq 10$ years $)$ ). Second, the risk of CC in the 86 sectors and three risk groups was compared with the risk of CC in the general Dutch population which was used as the baseline reference risk. To this end we calculated standardised incidence ratios (SIRs) of CC (overall, proximal and distal) in men and women separately (and overall) by dividing the observed number of CC diagnoses in a sector or risk group by the expected number of diagnoses based on age-matched (5-year bands), gendermatched, calendar year-matched (1-year bands) and subsite-matched CC IRs in the Dutch population. For the sectors a stratified analysis was done for the age groups 
Table 1 Incidence rates (IRs) of colon cancer (overall, proximal and distal) in the employed population

\begin{tabular}{|c|c|c|c|c|c|c|}
\hline & \multicolumn{2}{|c|}{ Colon cancer-overall } & \multicolumn{2}{|c|}{ Proximal colon cancer } & \multicolumn{2}{|c|}{ Distal colon cancer } \\
\hline & $\mathbf{N}$ & $\mathrm{IR}^{\star}(95 \% \mathrm{CI})$ & $\mathbf{N}$ & $\mathrm{IR}^{*}(95 \% \mathrm{CI})$ & $\mathbf{N}$ & $\mathrm{IR}^{\star}(95 \% \mathrm{Cl})$ \\
\hline All & 44778 & 3.03 (3.01 to 3.06$)$ & 21515 & $1.46(1.44$ to 1.48$)$ & 23263 & $1.58(1.56$ to 1.60$)$ \\
\hline Females & 15332 & 2.30 (2.27 to 2.34$)$ & 8028 & 1.21 (1.18 to 1.23$)$ & 7304 & 1.10 (1.07 to 1.12$)$ \\
\hline \multicolumn{7}{|l|}{ Age group } \\
\hline$\geq 50$ years & 39299 & 8.65 (8.57 to 8.74$)$ & 18695 & 4.12 (4.06 to 4.18$)$ & 20604 & 4.54 (4.47 to 4.60$)$ \\
\hline \multicolumn{7}{|c|}{ Exposure duration } \\
\hline$<2$ years & 3401 & 2.35 (2.27 to 2.43 ) & 1691 & $1.17(1.12$ to 1.23$)$ & 1710 & $1.18(1.13$ to 1.24$)$ \\
\hline $2-4$ years & 10959 & 2.73 (2.68 to 2.78 ) & 5511 & 1.37 (1.34 to 1.41$)$ & 5448 & $1.36(1.32$ to 1.39$)$ \\
\hline $5-9$ years & 14376 & 2.86 (2.81 to 2.91$)$ & 7006 & 1.39 (1.36 to 1.43$)$ & 7370 & $1.47(1.43$ to 1.50$)$ \\
\hline $5-9$ years & 9649 & 1.96 (1.93 to 2.00$)$ & 4806 & 0.98 (0.95 to 1.01$)$ & 4843 & 0.99 (0.96 to 1.01$)$ \\
\hline$\geq 10$ years & 30706 & 4.75 (4.70 to 4.80$)$ & 14463 & 2.24 (2.20 to 2.27$)$ & 16243 & 2.51 (2.48 to 2.55$)$ \\
\hline
\end{tabular}

*Incidence rate (IR) per 10000 person-years at risk.

†Period between start at-risk period and colon cancer diagnosis.

$<50$ years and $\geq 50$ years, while for the three risk groups, stratified analyses were done by subsite, gender, age group (20-39; 40-49; $\geq 50$ years), duration and latency. The $95 \%$ CIs for the SIRs were calculated assuming a Poisson distribution. In the analyses, $\mathrm{p}$ values $<0.05$ were considered statistically significant. Statistical analysis was performed using Stata V.16 (StataCorp LP, College Station, USA).

\section{Patient and public involvement}

No patients were involved.

\section{RESULTS}

\section{Cohort description}

The total cohort comprised 11136434 individuals with registered employment in (part of) the study period. The majority of the cohort consisted of men (54\%), although the percentage of women increased over the years. CC was diagnosed in 44778 individuals over the whole study period (2000-2016), corresponding to an overall average IR of $3.03(95 \%$ CI 3.01 to 3.06) CC cases per 10000 person-years at risk (table 1$)$. For both colon subsites, the IR was higher in men than in women (table 1). On average, women were diagnosed with $\mathrm{CC}$ at a lower age (median: 57.4 years; IQR: 50.6-62.8) as compared with men (median: 61 years; IQR: 55.1-65.9). Online supplementary table S1 and S2 show the SIRs for proximal, distal and overall CC among men and women, respectively, with employment history in at least 1 of the 84 different sectors. SIRs for overall CC ranged from 0.68 to 1.45 in men and 0.66 to 2.53 in women (online supplementary tables S1 and S2). The SIRs of CC in the age group under 50 years versus above 50 years differed substantially within and between sectors (online supplementary table S3). Among sectors with at least 10 observed CC diagnoses in both age groups, SIRs differed on average $12.5 \%$ (range: $0 \%-48 \%$ ) between the two age groups within a sector. For overall CC, a significantly increased risk was observed in men, women and/or both combined for seven sectors, whereas for proximal and distal CC, this was three and six sectors, respectively. Significantly decreased risks were observed in nine sectors for overall CC, eight for proximal CC and six for distal CC for men, women and/or both combined.

\section{Occupations with increased risk}

Significantly elevated SIRs for overall CC were found for men with employment history in manufacturing of rubber and plastics (SIR 1.14), sale and repair of motor vehicles (SIR 1.10), land transport (SIR 1.06), information service activities (SIR 1.45), (re)insurance and pension funding (SIR 1.12) and real estate activities (SIR 1.11) (figure 1). Concerning distal CC, significantly increased risk was observed for six sections, compared with one section for proximal part of the colon (figure 1). Within the section of rubber and plastic manufacturing, SIRs were increased for both colon subsites (proximal: SIR 1.10 (95\% CI 0.92 to 1.31 ); distal: SIR 1.17 (95\% CI 1.00 to $1.37)$ ). For the sale and repair of motor vehicles and land transport sections, SIRs were highest for the distal part, whereas for the information service activities the higher risk concerned the proximal colon only (SIR 1.88; $95 \%$ CI 1.25 to 2.83 ) (figure 1). Among men with employment history in (re)insurance and real estate, the risk 


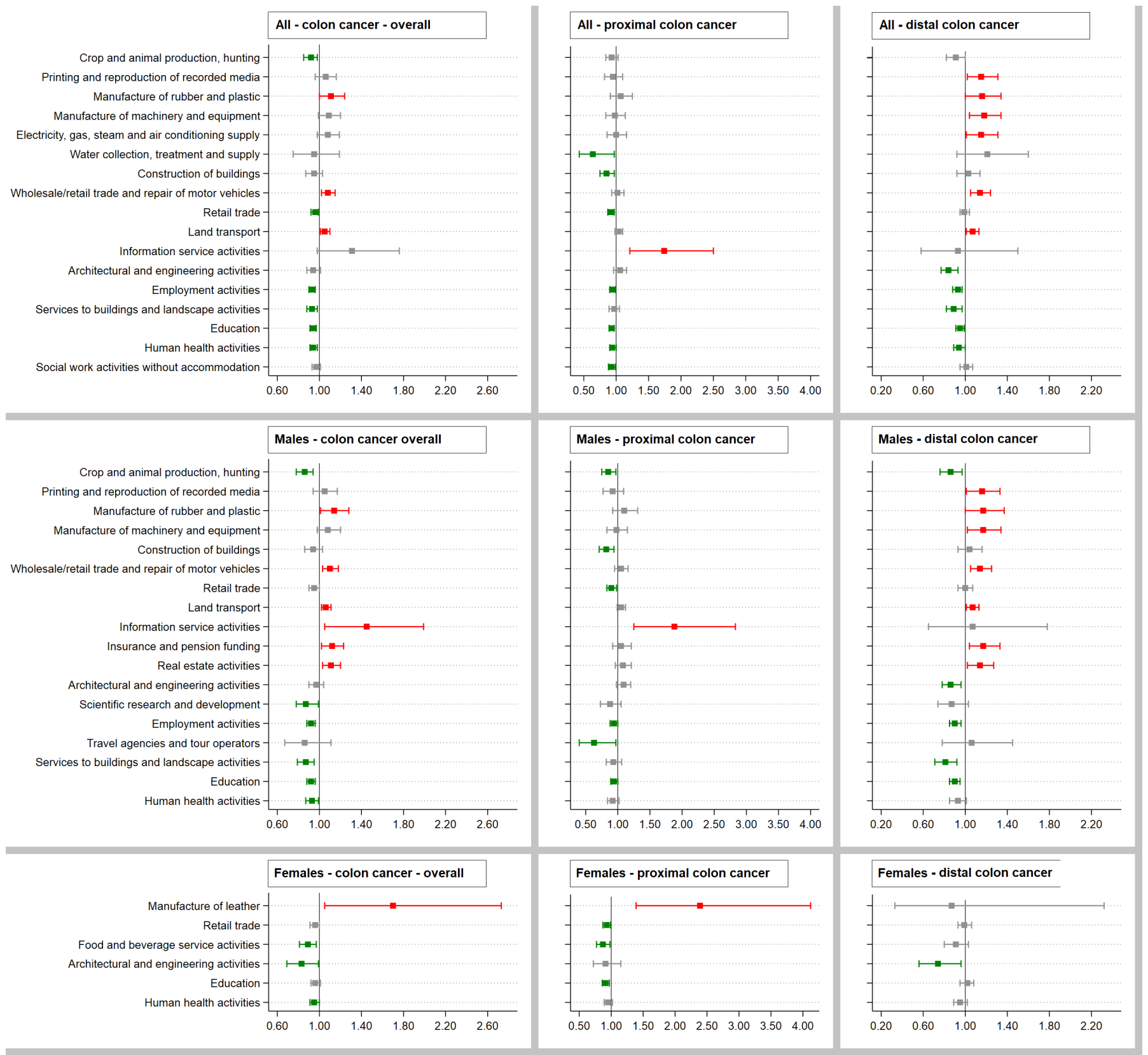

Figure 1 Standardised incidence ratios (SIRs) (squares) with 95\% Cls (bars) of colon cancer (overall, proximal and distal) in the total employed population and in men and women separately per sector. Red, significantly increased SIR; green, significantly decreased SIR; grey, non-significant SIR.

was most pronounced for distal CC and among people aged $\geq 50$ years, as compared with the general population (average SIRs 1.19 (range 1.04 to 1.35 ) and 1.13 (range 1.01 to 1.26$)$, respectively). Additionally, an increased risk concerning only the distal colon was observed among those with employment history in printing and reproduction of recorded media (SIR 1.16) and manufacturing of machinery (SIR 1.17), with the highest SIRs in the older age group and among people with long-term exposure. Among women, a significant increased SIR for overall CC was only observed for those employed in manufacturing of leather, with a SIR of 2.39 (95\% CI 1.39 to 4.12) for proximal CC and a SIR of 0.87 (95\% CI 0.33 to 2.32) for distal CC, although the observed numbers were relatively low.

\section{Occupations with decreased risk}

Among men, for 10 sectors, significantly decreased risks were observed, of which three were significant for both colon subsites (figure 1). In women, CC risk was significantly lower for five sectors. In the agricultural sector (crop and animal production), SIRs of 0.85 (95\% CI 0.75 to 0.97 ) and 0.86 (95\% CI 0.76 to 0.97 ) for distal CC were found in men, whereas for women the SIRs were slightly higher than 1, though not significant. The SIR for proximal CC in men was particularly low in the age group $\geq 50$ 
years (SIR $0.83 ; 95 \%$ CI 0.72 to 0.96 ), compared with the group under 50 years (SIR 0.99; $95 \%$ CI 0.71 to 1.37 ). The opposite was true for distal CC where the SIR for individuals $<50$ years was 0.64 (95\% CI 0.40 to 1.01 ) ( $\geq 50$ years: SIR $0.88 ; 95 \%$ CI 0.78 to 1.00 ). Within the education sector and the sector of retail trade, significant lower risks of proximal CC were observed for both men and women (figure 1). Moreover, lower risk of distal CC was found for men (SIR 0.86; 95\% CI 0.78 to 0.96 ) and women (SIR $0.74 ; 95 \%$ CI 0.56 to 0.96 ) with employment history in architectural and engineering activities. In the sector of food and beverage service activities (eg, cooks, waiters) the risk of overall $\mathrm{CC}$ and proximal CC was lower for women exclusively (SIR 0.87 ; $95 \%$ CI 0.77 to 0.98 ). Similarly, a significant, though marginal lower risk of overall CC was observed for the human healthcare sector (SIR $0.95 ; 95 \%$ CI 0.91 to 1.00$)$ in women. In this sector, the risk appeared lower for overall CC in the age group $\geq 50$ years (online supplementary table S3).

\section{Risk groups}

We also assessed specifically the incidence of CC in three groups with increased occupational exposure to zoonotic pathogens with oncogenic potential like Salmonella, as showed in a previous study. ${ }^{28}$ All three groups showed a marginally decreased risk for overall CC (table 2). Within the group involved in the sale of animal-derived food products, the SIRs were lowest for proximal CC (SIR 0.81; $95 \%$ CI 0.68 to 0.97 ), whereas for distal CC, the SIRs were above 1 for both men and women (table 2).

\section{DISCUSSION}

In this study, we linked two nationwide registries to assess potential associations between occupation (history) and CC incidence in The Netherlands in order to identify possible risk-conferring exposures in the workplace for CC development. Moreover, we looked at specific occupations for which an increased risk of infection with zoonotic pathogens like Salmonella has been found ${ }^{28}$, as Salmonella infection has shown to promote colon carcinogenesis in both epidemiological ${ }^{14}$ and experimental ${ }^{11} 1330$ studies. In contrast to other malignancies, the magnitude of occupation as risk factor for CC is relatively small compared with the major nutritional and lifestyle-related risk factors. It is also more difficult to quantify due to confounding factors (eg, smoking, physical activity), which are shared between some and differ substantially between other occupational groups. ${ }^{20} 223132$ This nationwide study in a high-income country covering a broad range of occupational sectors therefore wants to contribute to the existing knowledge on the occupational exposures associated with increased CC risk.

We found significantly increased risks for CC in several occupational sectors. Most of the results of this study were confirmatory in nature and mirrored previous observations available in the literature. For instance, significantly increased risks of (overall, proximal and/or distal) CC were found in multiple industrial sectors with potential exposure to chemicals, including the manufacturing of rubber and plastics, machinery and leather, as well as the printing sector. Extensive research has been done to assess the carcinogenic risk of exposures to, for example, benzene, solvents and dyes in these industries. While the causal relations between, for example, working in the rubber industry and bladder cancer and leukaemia, ${ }^{33}$ and working in the leather industry and pancreatic cancer, ${ }^{34}$ are well documented, the association with CC is more ambiguous. In a meta-analysis assessing occupational exposure and CC risk, relative risks of 1.16 (95\% CI 0.99 to 1.36) for the rubber and plastic industry, 1.49 (95\% CI 0.90 to 2.46) for the leather industry and 1.80 (95\% CI 1.20 to 2.70) for the printing sector were reported. ${ }^{9}$

A significantly increased risk of CC among people occupationally exposed to Salmonella via live animals or manure or through working in the sale of animal-derived food products, was not observed here. In the past decade, a growing number of experimental studies have unravelled the pathways by which pathogenic bacteria contribute to the development of cancer in the gastrointestinal tract. On infection, non-typhoidal Salmonella hijacks the host cell biology by introducing several effector proteins into the host cell. Specifically, acetyltransferase AvrA suppresses the immune response and apoptosis by inhibiting the host-signalling pathway NF- $\kappa \beta$ while enhancing epithelial cell proliferation by $\beta$-catenin signalling-pathway activation. ${ }^{1135}$ Similarly, SopB-, SopE-, SopE2- and SptP-effector proteins can facilitate transformation of pre-transformed host cells by activating the AKT-pathways and MAPKpathways. ${ }^{11}$ This was shown in a study of Scanu $e t$ al where mouse fibroblast and gallbladder organoids underwent irreversible transformation under conditions of an inactivated p53 tumour suppressor gene and an overexpressed c-MYC oncogene ${ }^{13}$ Besides laboratory evidence, the risk of developing proximal CC was found to be over twofold higher in people with a registered severe Salmonella infection in the past (SIR 2.12; 95\% CI 1.38 to 3.09). ${ }^{14}$ This risk was specifically higher for individuals infected with Salmonella Enteritidis (SIR 2.97; 95\% CI 1.73 to 4.76) and people aged $<60$ years at time of infection (SIR 1.54; $95 \%$ CI 1.09 to 2.10$).{ }^{14}$ Also, we showed in an earlier study that the risk of suffering severe salmonellosis was higher among people working with live animals or animal manure (SIR 1.82; 95\% CI 1.49 to 2.23) and among people working in the sale of animal-derived food products (SIR 1.55; 95\% CI 1.24 to 1.93 ) ${ }^{27}$ While these prior epidemiological studies focused on severe salmonellosis, here we particularly looked at the risk of CC after possible long-term occupational exposure to Salmonella, not per se leading to clinically-overt salmonellosis. The risk of CC in people working with live animals or manure appeared to be slightly reduced as compared with the general population. Acquired immunity against Salmonella in people with frequent exposure to such pathogens could also be an explanation for the observed findings, as the bacterium is more rapidly cleared from the body leaving less time 


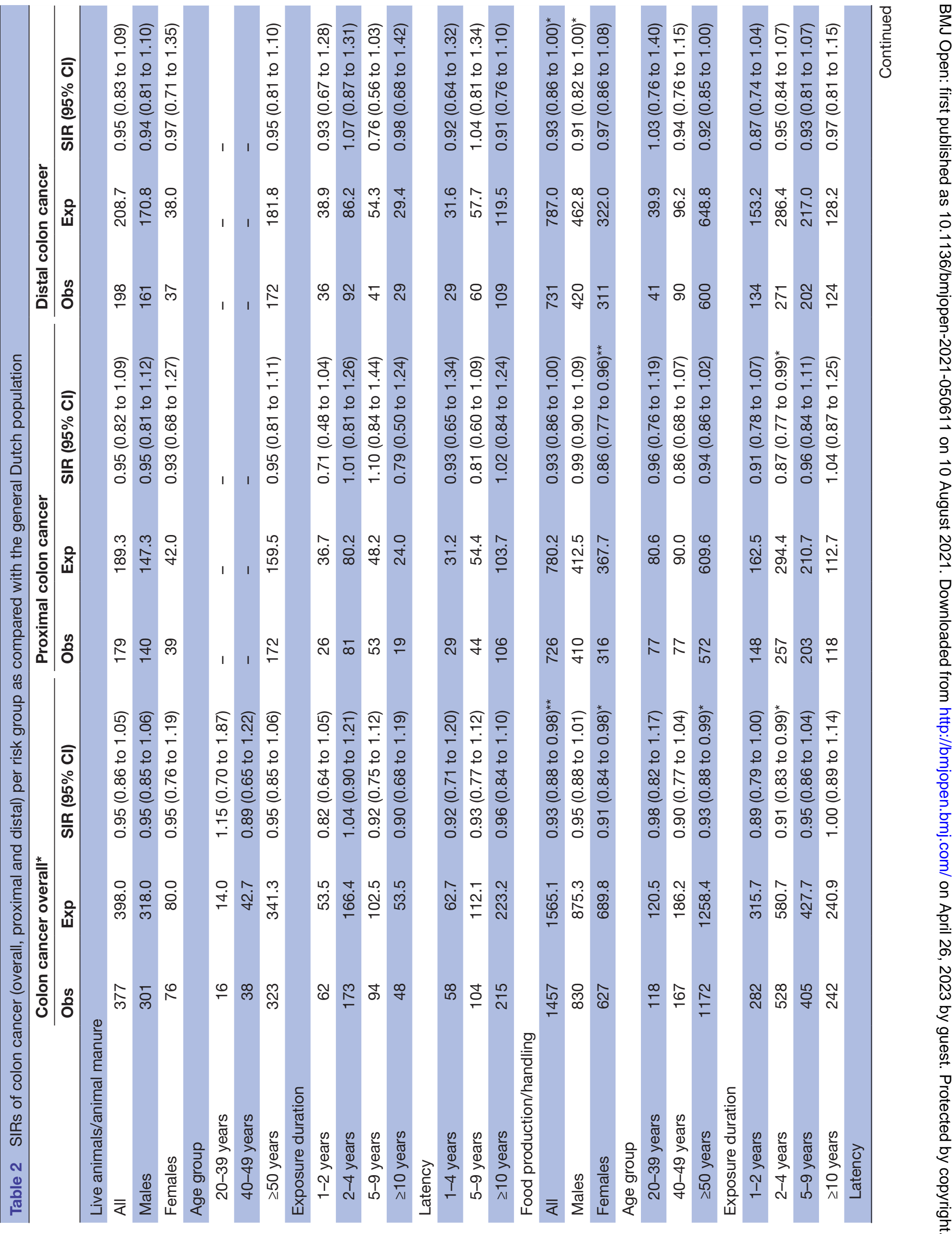




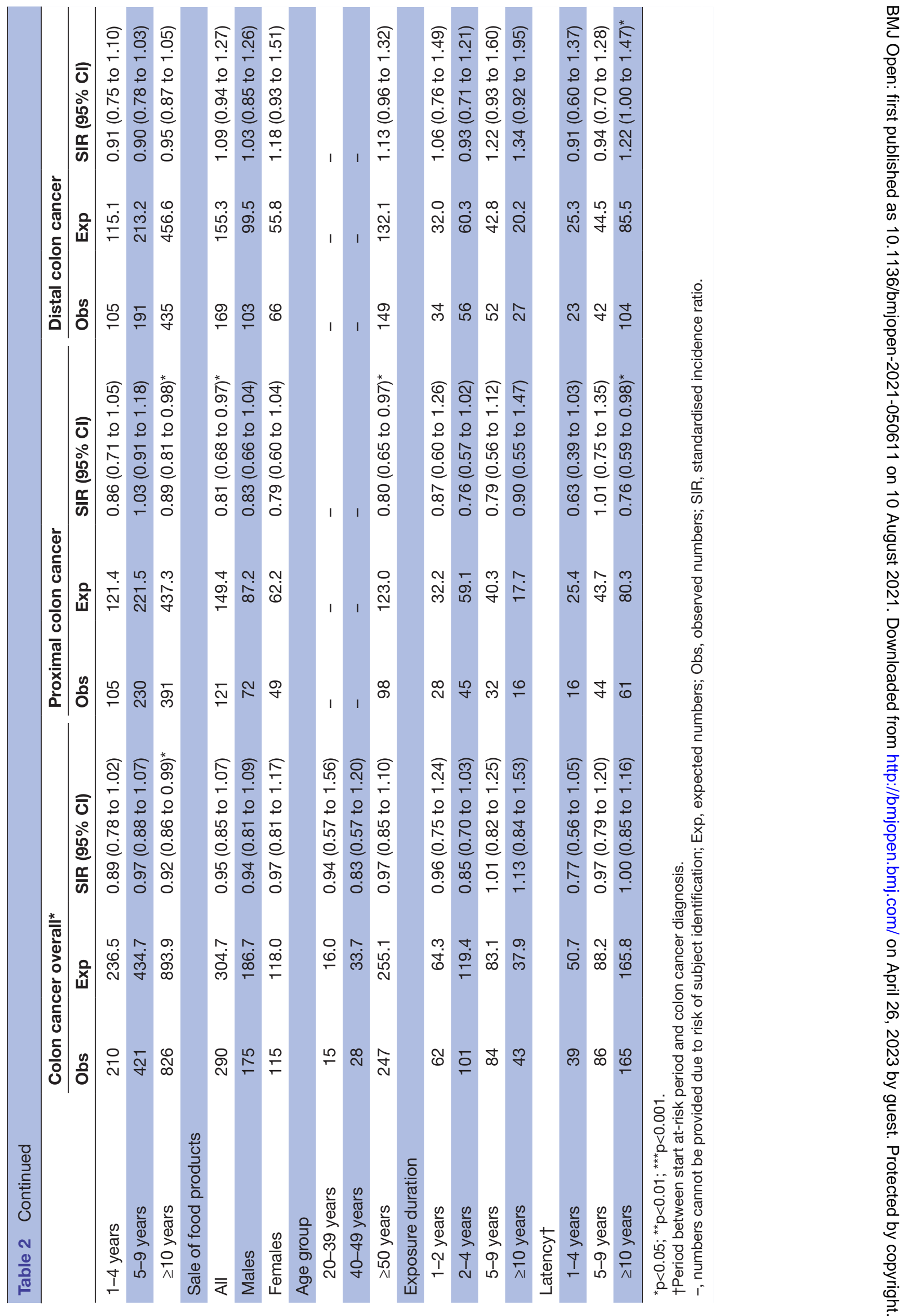


for Salmonella to induce cellular transformation. Acquired immunity in the occupationally exposed population has been shown for Campylobacter. ${ }^{36}$ As both pathogens are epidemiologically comparable in that respect, a similar mechanism can be assumed for Salmonella. In addition, it is possible that the Salmonella serovars in livestock differ from those contributing to human cell transformation. Unravelling the exact molecular mechanism by which Salmonella contributes to CC development could clarify this.

Extensive research into the risk of different forms of cancer among farmers has been done in the past, most of which found a reduced risk of CC as compared with non-farmers. ${ }^{9} 3138$ On the one hand, this may be related to the beneficial effect of increased physical activity (a known protective factor for CC) of people working in the agricultural sector, which might therefore outweigh other risk factors. ${ }^{39}$ Similarly, lower smoking rates have been reported among farmers compared with other occupational groups, which might have reduced the risk of developing $\mathrm{CC}$ as well, ${ }^{40}$ though risk estimates only slightly differed with and without adjustment for tobacco use and alcohol consumption in a large European cohort study. ${ }^{20}$ Although a previous study reported an increased CC incidence among poultry farmers, this could not be confirmed here. ${ }^{24}$ With regard to people working with raw meat, some studies reported a slightly increased (often non-significant) risk for overall CC among butchers and employees of meat-processing plants, however, a pooled analysis of multiple studies did not reveal a significant association. ${ }^{941}$ While physical activity can reduce the risk of CC up to $24 \%,{ }^{42}$ we did not observe a clear overall risk difference across sectors with a higher level of occupational physical activity versus more sedentary sectors (online supplementary tables S2 and S3). Nonetheless, SIRs of CC were significantly increased for three sectors, with mainly sedentary jobs, including the sectors of information service activities, real estate and insurance (figure 1). Conversely, significant risk deficit was found for a number of sectors with limited sedentary professions such as construction workers, farmers, teachers, the retail trade sector, the health sector and the services to buildings and landscapes sector (ie, interior cleaning of buildings and maintenance of public parks and gardens) (figure 1). Previous studies showed non-significant risk estimates close to 1 for both the education sector and the health sector, ${ }^{91}$ whereas for construction workers a significantly reduced risk of $5 \%-20 \%$ was found earlier. ${ }^{31}$ Also, for some sectors, particularly those associated with higher education and income, it is plausible that the lower CC risk is partly explained by an average healthier lifestyle, as it was previously shown that smoking rates and overweight/obesity were lower among teachers as compared with non-teachers. ${ }^{43}$

Apart from differences in incidence ratios across sectors, we found small differences between the sexes within some sectors. The NACE-code(s) linked to an individual person are based on the economic activity of the company/organisation at which he/she is employed, rather than the actual job task or individual measurements. Hence, due to this limitation, we could not disentangle possible gender disparities resulting from different job tasks of men versus women within a sector. Likewise, people might have been misclassified into a high risk group while their actual occupation does not involve exposure to zoonotic pathogens (eg, people with an office job at a slaughterhouse company). Also, whether an individual is working part-time or full-time was not registered at the person-level in the occupational records. Hence, this might have led to an overestimation of the exposure duration of women as compared with men, as in The Netherlands over $70 \%$ of women have a part-time job. ${ }^{44}$ Furthermore, although working environments in, for example, industries have become safer in the last decades with regard to exposure to hazardous/carcinogenic substances, ${ }^{45}$ SIRs were not consistently higher in those diagnosed with $\mathrm{CC}$ at an age of $\geq 50$ years compared with the younger age group (online supplementary table S3). Probably, the study period is too small to evaluate potential causes of a risk difference between age groups within sectors. For this study, we lacked information at the individual level about emigration. This has, to some extent, led to an underestimation of the cancer risk as a result of the overestimation of the total number of person-years at risk. Moreover, we lacked information about major risk factors, such as smoking, dietary habits, alcohol consumption and body weight, as these data are not usually routinely collected at the population level in national registries. Given that tobacco use and alcohol intake differ between occupational groups, there is evidence that adjustment for these variables could yield slightly different risk estimates. ${ }^{20}{ }^{46}$ Likewise, consumption of red and processed meat, another risk factor for CC, is inversely correlated with income and educational level. ${ }^{47-49}$ Yet, adjustment for these time-varying risk factors is impossible in a registry-based study with national coverage such as ours, and would require another type of study design.

In conclusion, only a few significant differences in CC incidence as a function of occupational exposures in different sectors were observed. This is unlike other forms of cancer, but is consistent with other literature on occupational risks of CC. The occupational exposures associated with increased CC risk were mainly those in the industrial sectors with potential exposure to toxic chemicals, such as the manufacturing of rubber and plastics, machinery and leather and the printing sector. These observations stress the need of continuous improvement of workplace-safety as well as more research in the future to assess whether these policies adequately reduce the incidence of cancers related to occupation. A significantly increased risk of CC among people occupationally exposed to live animals or manure or working in the sale of animal-derived food products (ie, the groups with increased salmonellosis risk) was not observed. This may be related to both the beneficial effect of increased physical activity (a known 
protective factor for $\mathrm{CC}$ ) of people working in the agricultural sector, which might outweigh other risk factors, as well as an overestimation of the number of people truly occupationally exposed to zoonotic pathogens due to the lack of detailed job content data at the individual level. Large population-based epidemiological studies based on national registries, such as the present study, have the advantage to allow for inference from available large data sets, providing an inventory of differences in CC incidence among occupational sectors that helps understanding the epidemiology of CC from a public health perspective. Yet, there are many other factors playing a role in CC development that cannot be properly controlled for in this type of studies. Therefore, understanding how different factors contribute to cancer formation can result in the design of studies with defined and coherent groups to limit the number of variables. Yet, the contribution of occupation to CC is limited regardless of the differences in the actual activity during the job.

Contributors All authors (JD, LMG, EF, JN) conceived and designed the study. JD performed the data analysis together with LMG. JD, LMG, EF and JN participated in critical interpretation of the results. JD drafted the paper, LMG, EF and JN contributed to the drafting. All authors contributed to the revision of the manuscript.

Funding This study was supported by the Dutch Ministry for Public Health, Welfare and Sport via the 'ZonMw' grant no. 522004001.

Competing interests None declared.

Patient consent for publication Not required.

Provenance and peer review Not commissioned; externally peer reviewed.

Data availability statement All data relevant to the study are included in the article or uploaded as supplementary information.

Supplemental material This content has been supplied by the author(s). It has not been vetted by BMJ Publishing Group Limited (BMJ) and may not have been peer-reviewed. Any opinions or recommendations discussed are solely those of the author(s) and are not endorsed by BMJ. BMJ disclaims all liability and responsibility arising from any reliance placed on the content. Where the content includes any translated material, BMJ does not warrant the accuracy and reliability of the translations (including but not limited to local regulations, clinical guidelines, terminology, drug names and drug dosages), and is not responsible for any error and/or omissions arising from translation and adaptation or otherwise.

Open access This is an open access article distributed in accordance with the Creative Commons Attribution Non Commercial (CC BY-NC 4.0) license, which permits others to distribute, remix, adapt, build upon this work non-commercially, and license their derivative works on different terms, provided the original work is properly cited, appropriate credit is given, any changes made indicated, and the use is non-commercial. See: http://creativecommons.org/licenses/by-nc/4.0/.

ORCID iD

Janneke Duijster http://orcid.org/0000-0002-9197-9079

\section{REFERENCES}

1 Ferlay J, Ervik M, Lam F. Global cancer Observatory: cancer today. Lyon, France: International Agency for Research on Cancer, 2018. https://gco.iarc.fr/today

2 IKNL. Overleving darmkanker, 2020. Available: https://www.iknl.nl/ kankersoorten/darmkanker/registratie/overleving

3 Siegel RL, Torre LA, Soerjomataram I, et al. Global patterns and trends in colorectal cancer incidence in young adults. Gut 2019;68:2179-85.

4 Vuik FE, Nieuwenburg SA, Bardou M, et al. Increasing incidence of colorectal cancer in young adults in Europe over the last 25 years. Gut 2019;68:1820-6.

5 Wei EK, Giovannucci E, Wu K, et al. Comparison of risk factors for colon and rectal cancer. Int J Cancer 2004;108:433-42.
6 Liang PS, Chen T-Y, Giovannucci E. Cigarette smoking and colorectal cancer incidence and mortality: systematic review and metaanalysis. Int J Cancer 2009;124:2406-15.

7 Lynch BM. Sedentary behavior and cancer: a systematic review of the literature and proposed biological mechanisms. Cancer Epidemiol Biomarkers Prev 2010;19:2691-709.

8 Offermans NSM, Vermeulen R, Burdorf A, et al. Occupational asbestos exposure and risk of esophageal, gastric and colorectal cancer in the prospective Netherlands cohort study. Int $J$ Cancer 2014;135:1970-7.

9 Oddone E, Modonesi C, Gatta G. Occupational exposures and colorectal cancers: a quantitative overview of epidemiological evidence. World J Gastroenterol 2014;20:12431.

10 Talibov M, Sormunen J, Hansen J, et al. Benzene exposure at workplace and risk of colorectal cancer in four Nordic countries. Cancer Epidemiol 2018;55:156-61.

11 van Elsland D, Neefjes J. Bacterial infections and cancer. EMBO Rep 2018;19:e46632.

12 Kikuchi S. Epidemiology of Helicobacter pylori and gastric cancer. Gastric Cancer 2002;5:6-15.

13 Scanu T, Spaapen RM, Bakker JM, et al. Salmonella manipulation of host signaling pathways provokes cellular transformation associated with gallbladder carcinoma. Cell Host Microbe 2015;17:763-74.

14 Mughini-Gras L, Schaapveld M, Kramers J, et al. Increased colon cancer risk after severe Salmonella infection. PLoS One 2018;13:e0189721.

15 Duijster JW, Hansen JV, Franz E, et al. Association between Salmonella infection and colon cancer: a nationwide registry-based cohort study. Epidemiol Infect 2021;149:1-19.

16 Lu R, Wu S, Zhang Y-G, et al. Salmonella protein AvrA activates the STAT3 signaling pathway in colon cancer. Neoplasia 2016;18:307-16.

17 Lu R, Bosland M, Xia Y, et al. Presence of Salmonella AvrA in colorectal tumor and its precursor lesions in mouse intestine and human specimens. Oncotarget 2017;8:55104-15.

18 Pleguezuelos-Manzano C, Puschhof J, Rosendahl Huber A, et al. Mutational signature in colorectal cancer caused by genotoxic $\mathrm{pks}^{+}$ E. coli. Nature 2020;580:269-73.

19 Dziubańska-Kusibab PJ, Berger H, Battistini F, et al. Colibactin DNAdamage signature indicates mutational impact in colorectal cancer. Nat Med 2020;26:1063-9.

20 Kjaerheim K, Haldorsen T, Lynge E, et al. Variation in Nordic workrelated cancer risks after adjustment for alcohol and tobacco. Int $J$ Environ Res Public Health 2018;15:2760.

21 Lerro CC, Hofmann JN, Andreotti G, et al. Dicamba use and cancer incidence in the agricultural health study: an updated analysis. Int $J$ Epidemiol 2020;49:1326-37.

22 Pukkala E, Martinsen JI, Lynge E, et al. Occupation and cancer follow-up of 15 million people in five Nordic countries. Acta Oncol 2009;48:646-790.

23 Papantoniou K, Devore EE, Massa J, et al. Rotating night shift work and colorectal cancer risk in the nurses' health studies. Int J Cancer 2018;143:2709-17.

24 Boulanger M, Morlais F, Bouvier V, et al. Digestive cancers and occupational asbestos exposure: incidence study in a cohort of asbestos plant workers. Occup Environ Med 2015;72:792-7.

25 Beane Freeman LE, Deroos AJ, Koutros S, et al. Poultry and livestock exposure and cancer risk among farmers in the agricultural health study. Cancer Causes Control 2012;23:663-70.

26 Paschke S, Jafarov S, Staib L, et al. Are colon and rectal cancer two different tumor entities? A proposal to abandon the term colorectal cancer. Int J Mol Sci 2018;19:2577.

27 Eurostat. NACE Rev. 2-Statistical classification of economic activities, 2008. Available: http://ec.europa.eu/eurostat/web/nacerev2

28 Duijster JW, Franz E, Neefjes JJC, et al. Occupational risk of salmonellosis and campylobacteriosis: a nationwide populationbased registry study. Occup Environ Med 2019;76:617-24.

29 IKNL. NKR cijfers - dikkedarmkanker, 2020. Available: http://iknl.nl/ nkr-cijfers

30 Zha L, Garrett S, Sun J. Salmonella Infection in Chronic Inflammation and Gastrointestinal Cancer. Diseases 2019;7:28.

31 Chow WH, Malker HS, Hsing AW, et al. Occupational risks for colon cancer in Sweden. J Occup Med 1994;36:647-51.

32 Lerro CC, Koutros S, Andreotti G, et al. Cancer incidence in the agricultural health study after 20 years of follow-up. Cancer Causes Control 2019;30:311-22.

33 Marant Micallef C, Shield KD, Baldi I, et al. Occupational exposures and cancer: a review of agents and relative risk estimates. Occup Environ Med 2018;75:604-14. 
34 Rastogi SK, Kesavachandran C, Mahdi F, et al. Occupational cancers in leather tanning industries: a short review. Indian J Occup Environ Med 2007;11:3.

35 Sun J, Hobert ME, Rao AS, et al. Bacterial activation of beta-catenin signaling in human epithelia. Am J Physiol Gastrointest Liver Physiol 2004;287:G220-7.

36 de Perio MA, Niemeier RT, Levine SJ, et al. Campylobacter infection in poultry-processing workers, Virginia, USA, 2008-2011. Emerg Infect Dis 2013;19:286-8.

37 Cawthraw SA, Lind L, Kaijser B, et al. Antibodies, directed towards Campylobacter jejuni antigens, in sera from poultry abattoir workers. Clin Exp Immunol 2000;122:55-60.

38 Blair A, Freeman LB. Epidemiologic studies in agricultural populations: observations and future directions. J Agromedicine 2009;14:125-31.

39 Haggar FA, Boushey RP. Colorectal cancer epidemiology: incidence, mortality, survival, and risk factors. Clin Colon Rectal Surg 2009;22:191-7.

40 McCurdy SA, Sunyer J, Zock J-P, et al. Smoking and occupation from the European community respiratory health survey. Occup Environ Med 2003;60:643-8.

41 Guo Z-L, Wang J-Y, Li Y-S, et al. Association between butchers and cancer mortality and incidence: a systematic review and metaanalysis. Medicine 2017;96:e8177.

42 Wolin KY, Yan Y, Colditz GA, et al. Physical activity and colon cancer prevention: a meta-analysis. Br J Cancer 2009;100:611-6.
43 Gilbert F, Richard J-B, Lapie-Legouis P, et al. Health behaviors: is there any distinction for teachers? A cross-sectional nationwide study. PLoS One 2015;10:e0120040.

44 Statistics Netherlands. Werkenden, 2021. Available: https://www.cbs. $\mathrm{nl} / \mathrm{nl}$-nl/visualisaties/dashboard-arbeidsmarkt/werkenden [Accessed 1 Jul 2021].

45 Jongeneel WP, Eysink PED, Theodori D. Work-Related cancer in the European Union: size impact and options for further prevention 2016.

46 Kuntz B, Kroll LE, Hoebel J, et al. [Time trends of occupational differences in smoking behaviour of employed men and women in Germany : Results of the 1999-2013 microcensus]. Bundesgesundheitsblatt Gesundheitsforschung Gesundheitsschutz 2018;61:1388-98.

47 Clonan A, Roberts KE, Holdsworth M. Socioeconomic and demographic drivers of red and processed meat consumption: implications for health and environmental sustainability. Proc Nutr Soc 2016;75:367-73.

48 Stoll-Kleemann S, Schmidt UJ. Reducing meat consumption in developed and transition countries to counter climate change and biodiversity loss: a review of influence factors. Reg Environ Change 2017;17:1261-77.

49 Kloosterman R, Akkermans M, Reep C. Vleesconsumptie, 2021. Available: https://www.cbs.nl/nl-nl/longread/rapportages/2021/ klimaatverandering-en-energietransitie-opvattingen-en-gedragvan-nederlanders-in-2020/6-vleesconsumptie [Accessed 1 Jul 2021] 